\title{
O Processo de Identificação e Exploração de Oportunidade Empreendedora com base no Modelo de Aprendizagem Organizacional 4I
}

\author{
The Identification and Exploitation of Entrepreneurial \\ Opportunity based on the Model of Organizational Learning $4 i$
}

\author{
Adson da Rocha Pita Albuquerque \\ Mestre em Administração. Universidade Federal de Sergipe. Aracaju, SE, Brasil.E-mail: adsonpita@gmail.com \\ Rivanda Meira Teixeira \\ Doutora em Administração pela Cranfield University na Inglaterra. Professora do programa de Mestrado em Administração da \\ Universidade Federal de Sergipe. Aracaju, SE, Brasil. E-mail: rivandateixeira@gmail.com
}

\section{Resumo}

A análise da oportunidade empreendedora é um tema central no campo do empreendedorismo e se refere à descoberta, à identificação e à exploração de oportunidades de negócios. O objetivo deste estudo é analisar o processo de identificação e de exploração de oportunidade empreendedora com base no Modelo de Aprendizagem Organizacional 4i de Crossan, Lane e White. Este trabalho é qualitativo e utiliza a estratégia de estudo de caso único. As evidências mostram que os empreendedores passaram pelo estágio de intuição, no qual a identificação de oportunidade se inicia com a idealização do negócio. $\mathrm{Na}$ fase de interpretação, a oportunidade se desenvolveu na rede informal dos empreendedores, especificamente com a família. $\mathrm{Na}$ fase de integração, a relação com a rede formal é essencial para a exploração da oportunidade. Por fim, a institucionalização ocorre quando a oportunidade é explorada, por meio das rotinas e dos processos internos, bem como do planejamento de expansão do negócio.

Palavras-chave: Aprendizagem Organizacional. Empreendedorismo. Oportunidade Empreendedora. Modelo de Aprendizagem Organizacional 4i.

\section{Abstract}

The analysis of entrepreneurial opportunity is a major theme in the field of entrepreneurship concerning the discovery, identification and exploration of business opportunity. This study aimed to analyze the process of identification and entrepreneurial opportunity to explore based on the Model of Organizational Learning 4i Crossan, Lane and White. This study is qualitative and uses the single case study strategy. Evidence shows that entrepreneurs passed by intuition stage, in which the opportunity identification begins with the business idealization. In the phase of interpretation, the opportunity developed in relation to the informal network of entrepreneurs, specifically with family. In the phase of integration, it was observed that the relationship with the formal network is an essential for the exploitation of opportunity. Finally the institutionalization happens when the opportunity is exploited, through the routines and processes as well as business expansion planning.

Keywords: Organizational Learning. Entrepreneurship. Entrepreneurial Opportunity Organizational Learning Model 4i. 


\section{INTRODUÇÃo}

O empreendedorismo é um campo de estudos amplo e dinâmico e refere-se ao estudo sobre a criação de organizações (LOW; McMILLAN, 1988; GARTNER, 1988). Pode ser definido ainda como aquele que estuda os empreendedores, examina suas atividades, características, efeitos econômicos e sociais e os métodos de apoio usados para facilitar a expressão da atividade empreendedora (FILION, 1997). Segundo Shane e Venkataraman (2000), o empreendedorismo envolve o estudo das fontes de oportunidades, os processos de descoberta, de avaliação e de exploração das oportunidades; e o conjunto dos indivíduos que descobrem, avaliam e exploram as oportunidades.

Para Short et al. (2010), o tema oportunidade(s) empreendedora(s) é um dos mais importantes dentro do campo do empreendedorismo e seu estudo é relevante pois representa um dos fatores de sobrevivência das empresas (FABRÍCIO; MACHADO, 2010). Ainda segundo Machado (2013), esse estudo leva a uma melhor compreensão sobre a criação e desenvolvimento de um empreendimento. Para Gartner (1988), só existe empreendedorismo se primeiramente houver oportunidades empreendedoras.

$\mathrm{O}$ ato de empreender, ou seja, de transformar uma ideia em realidade (empreendimento) é motivado, segundo o estudo do Global Entrepreneurship Monitor - GEM (2013), por necessidade ou oportunidade. Aqueles que são motivados por necessidade o fazem porque não lhes resta outra opção. Os empreendedores motivados por oportunidade, por sua vez, são impulsionados pela percepção (identificação) de alguma oportunidade e buscam explorá-la. O foco deste estudo é sobre o empreendedorismo por oportunidade. Os empreendedores por oportunidade são aqueles indivíduos que se lançam num empreendimento por terem identificado uma oportunidade de negócio, um nicho de mercado, ou uma oportunidade de retorno financeiro (CORRÊA; VALE, 2014).

Para esse estudo foi utilizado como base teórica o Modelo de Aprendizagem Organizacional 4i de Crossan, Lane e White (1999) e adaptado por Dutta e Crossan (2005). Segundo esse modelo, as oportunidades empreendedoras seguem quatro fases: intuição, interpretação, integração $e$ institucionalização, $e$ desenvolve-se em três níveis: individual, de grupo e or- ganizacional. O objetivo principal é analisar o processo de identificação e exploração de oportunidade empreendedora por parte de dois pequenos empreendedores segundo o Modelo de Aprendizagem Organizacional 4i de Crossan, Lane e White. Especificamente visa: 1) identificar o papel da intuição na identificação e exploração de oportunidade empreendedora; 2) verificar como ocorre a etapa de interpretação no processo de identificação e exploração de oportunidade empreendedora; 3) identificar o desenvolvimento da etapa de integração no processo de identificação e exploração de oportunidade empreendedora e 4) verificar como ocorre a institucionalização no processo de identificação e exploração de oportunidade empreendedora.

Este estudo está estruturado em quatro partes, além desta introdução. Na segunda parte está a fundamentação teórica, enfocando especialmente nos conceitos, definições, características e abordagens sobre oportunidade empreendedora, bem como a apresentação do modelo teórico adotado. Na terceira parte são apresentados os aspectos metodológicos adotados e a tipologia da pesquisa. Na quarta parte é destacada a descrição do caso. Por fim, a conclusão com as considerações finais.

\section{Oportunidade Empreendedora}

O empreendedorismo é um processo que começa com o reconhecimento de uma oportunidade empresarial e é seguido pelo desenvolvimento de uma ideia de como exercer essa oportunidade, a avaliação da viabilidade da oportunidade, o desenvolvimento do produto ou do serviço que será fornecido aos clientes, montagem de recursos humanos e financeiros, desenho organizacional, bem como a busca de clientes (SHANE; LOCKE; COLLINS, 2003).

As oportunidades empreendedoras se manifestam de diversas maneiras, tipos e abordagens. Para Smith, Matthews e Schenkel (2009), as oportunidades podem ser de dois tipos: oportunidade codificada e oportunidade tácita. A oportunidade codificada é quando ela pode ser claramente percebida e transmitida formalmente por meio de códigos, está bem documentada e é mais fácil de comunicar. A oportunidade tácita é aquela oportunidade que não está tão clara, é difícil de codificar e comunicar. 
Segundo Dutta e Crossan (2005), o estudo sobre oportunidade empreendedora é um fenômeno pouco compreendido. Para Fabrício e Machado (2010), o tema ainda é pouco explorado. Em pesquisa realizada na base SPELL (Scientific Periodicals Electronic Library), foram identificados apenas dez estudos, nos últimos dez anos, que tratam do assunto.

A oportunidade pode ser resultante de uma descoberta acidental ou como um processo desenvolvido ao longo do tempo ou ainda como uma construção pelo sujeito (MACHADO, 2013, p. 30). A identificação de oportunidade pode surgir de uma busca deliberada, de um legado ou de maneira totalmente casual e não deliberada (SHEPHERD; DETIENNE, 2005).

Duas correntes de pensamento emergem acerca do tema da oportunidade empreendedora (VAGHELY; JULIEN, 2010). De um lado a corrente que afirma que as oportunidades existem e estão à espera de serem descobertas (ALVAREZ; BARNEY, 2007). No outro lado há a corrente que defende que as oportunidades são criadas (VAGHELY; JULIEN, 2010).

A abordagem da descoberta trata as oportunidades como sendo objetos identificáveis e que estão lá fora para serem examinadas, mas apenas para aqueles que têm a capacidade de descobri-las e explorá-las (AUDRETSCH; ACS, 2003). Tais oportunidades são objetivas e podem ser observadas, ou encontradas. Nesta abordagem os indivíduos fazem uma varredura do ambiente para descobrir as oportunidades competitivas (EDELMAN; RENKO, 2010). Segundo a abordagem da descoberta, a natureza das oportunidades está associada às imperfeições do mercado (ALVAREZ; BARNEY, 2007; AUDRETSCH; ACS, 2003).

Os indivíduos que estão em busca de oportunidades, são aqueles que estão em "estado de alerta". Estado de alerta é um conceito atribuído a Kirzner (1979 apud TANG; KACMAR; BUSENITZ, 2012). O estado de alerta nada mais é do que um estado de atenção do indivíduo em relação ao seu ambiente (VALLIERE; 2013). Estado de alerta é a capacidade que o indivíduo tem para identificar oportunidades que são negligenciados por outros (TANG; KACMAR; BUSENITZ, 2012). No estado de alerta existem três elementos essenciais: 1) procura e busca de informação; 2) conexão de informações e 3) avaliações sobre oportunidades rentáveis (TANG; KACMAR; BUSENITZ, 2012). Segundo Faia, Rosa e Machado (2014), "O alerta empreendedor tem sido central no recente desenvolvimento da área do empreendedorismo".

A abordagem da criação de oportunidade se baseia na visão construcionista segundo a qual os empreendedores processam informações de uma forma interpretativista e constroem sua realidade a partir dessas informações (VAGHELY; JULIEN, 2010). Segundo esta abordagem, as oportunidades não podem ser reconhecidas ou descobertas, pois elas não pré existem, mas se manifestam para aqueles que buscam criar empreendimentos (SARASON; DEAN; DILLARD, 2006).

O modelo Causation e Effectuation de Sarasvathy (2001) aborda a criação de oportunidade. No processo causation, o empreendedor tem um objetivo e procura os meios para alcançá-lo. Assim, nesta abordagem, a oportunidade emerge a partir de uma avaliação analítica das informações disponíveis. No processo effectuation o objetivo não está claro, mas ele possui uma série de meios dados (o que o indivíduo possui ou está disponível) e com estes meios procurar selecionar os possíveis efeitos que podem ser criados. Para o processo effectuation as oportunidades não existem a priori, portanto, não podem ser reconhecidas ou descobertas. As oportunidades são, portanto, criadas a partir de um processo que envolve uma interação com o ambiente, suas contingências e principalmente com os stekeholders (FAIA; ROSA; MACHADO, 2014).

Em ambos os processos, a habilidade cognitiva do empreendedor tem papel importante. No processo causation a "cognição influencia a determinação prévia de objetivos e modos de ação, enquanto no effectuation, influencia no 'desenho de artefatos' em conjunto com outros atores" (AUGIER; SARASVATHY, 2004, p. 172 apud FAIA; ROSA; MACHADO, 2014).

\subsection{Oportunidade e Cognição}

Tanto a abordagem da descoberta, quanto a da criação de oportunidade prescindem da cognição (EDELMAN; RENKO, 2010; VAGHELY; JULIEN, 2010). A identificação de oportunidade se dá através de processos cognitivos (BARON, 2006).

Neste estudo, cognição pode ser entendida como "[...] as estruturas de conhecimento que as pessoas usam para fazer avaliações, julgamentos, ou decisões envolvendo a avaliação de oportunidades, criação $e$ 
crescimento de empresa" (MITCHELL et al., 2002, p. 97). Assim, é possível destacar os seguintes fatores relacionados à cognição e sua influência sobre as oportunidades: as informações e conhecimentos (RERUP, 2005; SMITH; MATTHEWS; SCHENKEL, 2009), experiência (UCBASARAN; WESTHEAD; WRIGHT, 2009), inteligência (BARON, 2006), criatividade (DIMOV, 2007a) e aprendizado (RAE, 2005).

O uso da informação é amplamente discutido no estudo de Rerup (2005). Em seu estudo afirma que as diferenças de informações e experiências fazem com que as pessoas enxerguem diferentes tipos de oportunidades e que o uso de informações e experiências individuais determina quem se tornará um empreendedor ou não. Para Shane e Venkataraman (2000), as oportunidades empreendedoras dependem das assimetrias de informação. Assimetria de informação diz respeito à forma desigual como a informação é distribuída entre os indivíduos (ECKHARDT; SHANE, 2003). Shane (2000) afirma ainda que cada pessoa possui estoques de informações individuais e isso é o que determina por que algumas pessoas descobrem oportunidades empreendedoras e outras não.

O conhecimento, por sua vez, pode ser definido como informação combinada com experiência, contexto, interpretação e reflexão (VAGHELY; JULIEN, 2010). Smith, Matthews e Schenkel (2009) fazem uma distinção entre informação e conhecimento: a informação é um atributo da oportunidade, enquanto o conhecimento é um atributo do indivíduo.

Os empreendedores altamente experientes buscam por oportunidades em áreas específicas nas quais eles já possuem um conhecimento considerável. Os processos cognitivos, principalmente a inteligência e a criatividade são importantes para a identificação de oportunidades (BARON, 2006). Para Dimov (2007b), a identificação de oportunidades envolve o uso de processos criativos para perceber novas ideias e colocá-las em prática. Para Baron e Shane (2007), a criatividade é um dos processos-chave do empreendedorismo. O conhecimento, na forma de experiência, tem sido investigado como um fator primordial para a capacidade de identificar oportunidades (CORBETT, 2005).

Entre as estruturas de conhecimento se insere o conceito de aprendizagem empreendedora. Aprendizagem empreendedora significa aprender a reconhecer e agir em oportunidades, interagir socialmente para iniciar, organizar e gerir empreendimentos (RAE, 2005). Para Kolb (1984), a aprendizagem se baseia na relação entre novas informações e experiência anterior para a criação de novos conhecimentos. Em seu estudo, Corbett (2007) trata das assimetrias (diferenças) de aprendizagem e como elas afetam a descoberta de oportunidades. Por causa dessas assimetrias nem todos os indivíduos são igualmente propensos a reconhecer uma oportunidade (SHANE; VENKATARAMAN, 2000).

Kolb (1984) desenvolveu a teoria de aprendizagem experiencial segundo a qual a aprendizagem se baseia na experiência para a criação de novos conhecimentos. Segundo ele, a aprendizagem experiencial consiste dos seguintes elementos: 1) o conhecimento existente; 2) o processo através do qual os indivíduos adquirem novas informações e experiências, e 3) a maneira pela qual, indivíduos transformam novas informações e experiências em novos conhecimentos.

O estudo de Ucbasaran, Westhead e Wright (2009) não apenas mostra a importância da experiência no contexto de reconhecimento e exploração de oportunidade, mas vai além ao explicar como uma pessoa que não possui experiência anterior pode compensar esta deficiência. Os autores afirmam que o empreendedor inicial deve investir no desenvolvimento de suas habilidades empreendedoras por meio da educação e formação.

\subsection{Oportunidade Empreendedora e o Modelo de Aprendizagem Organizacional 4i}

O conceito de aprendizagem organizacional é aplicado a diferentes campos de estudo (CROSSAN; LANE; WHITE, 1999). Recentemente, muitas empresas descobriram que a aprendizagem organizacional pode ajudar na melhoria de desempenho e promover crescimento (LUMPKIN; LICHTENSTEIN, 2005). Para eles, a aprendizagem organizacional vincula cognição à ação.

No estudo de Lumpkin e Lichtenstein (2005), em que eles tratam sobre a aprendizagem organizacional e o processo de reconhecimento de oportunidade e destacam três abordagens distintas sobre a aprendizagem organizacional: 1) aprendizagem comportamental: abordagem segundo a qual a organização 
responde às experiências repetindo comportamentos bem-sucedidos e evitando os que não foram; 2) aprendizagem cognitiva: afirma que o processo de criação do conhecimento pode gerar competencias organizacionais únicas e potenciais fontes de vantagem competitiva; 3) aprendizagem de ação: se preocupa com as crenças e a qualidade das interações entre os membros da organização que podem facilitar ou limitar as capacidades da empresa.

Para Dutta e Crossan (2005), o campo do empreendedorismo requer um alargamento de seu campo de pesquisa $e$ os estudos anteriores sobre oportunidade empreendedora tem tido um foco limitado. Assim, eles desenvolveram seu estudo buscando "[...] compreender o processo que envolve oportunidades empreendedoras adotando uma perspectiva de aprendizagem organizacional" (DUTTA; CROSSAN, 2005, p. 427). Os autores desenvolveram o modelo 4i (Figura 1) segundo o qual as oportunidades empreendedoras se desenrolam num processo de aprendizagem. $\mathrm{O}$ modelo integra as duas visões sobre oportunidade: visão cognitivista (descoberta) e a interpretativista (criação).

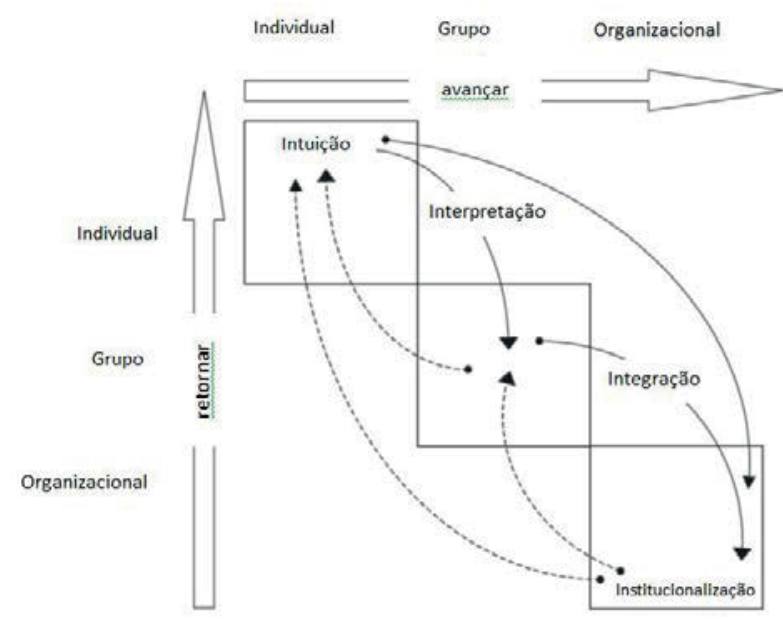

Figura 1: Aprendizagem organizacional como um processo dinâmico Fonte: Adaptada de Crossan, Lane e White (1999)

O modelo 4i envolve os processos de intuição, interpretação, integração $e$ institucionalização $e$ ocorrem ao longo de três níveis: individual, grupo e organizacional. Com a utilização do modelo $4 \mathrm{i}$ como uma lente teórica, é possível reconhecer a natureza dinâmica das oportunidades que se desenrolam e como os empreendedores se envolvem com elas (DUTTA; CROSSAN, 2005).

\subsubsection{Intuição}

A intuição encontra-se no nível individual do processo. Segundo Dutta e Crossan (2005), ela é a semente de qualquer ação empreendedora. Essa etapa do processo tem a ver com a reflexão pré-consciente de um indivíduo sobre uma ideia de negócio em potencial, é em grande parte subconsciente e envolve reconhecimento de padrões. A intuição pode assumir duas formas: a intuição do especialista $e$ a intuição empreendedora (DUTTA; CROSSAN, 2005). A intuição do especialista se apoia em reconhecimento de padrões e enfatiza a base de conhecimento que o indivíduo possui - está relacionada à abordagem da descoberta. A intuição empreendedora por sua vez confia menos na base de conhecimento do indivíduo, mas sim, em sua capacidade criativa para reconhecer as lacunas e identificar possibilidades - relaciona-se com a abordagem da construção (DUTTA; CROSSAN, 2005). Nesta etapa são usadas metáforas como forma de linguagem para que o empreendedor possa descrever para si mesmo ou para outros a sua ideia. Posteriormente uma linguagem literal é usada para nomear a metáfora.

\subsubsection{Interpretação}

A etapa de interpretação ocorre entre o nível individual e de grupo. A Interpretação é uma atividade social que acontece na interação do indivíduo com outros atores (CROSSAN; LANE; WHITE, 1999). Nesta etapa, o empreendedor compartilha sua ideia com membros de sua rede. Ele usa uma linguagem comum e através de diálogos procura melhorar o grau de interpretação da ideia original. Ou seja, a ideia deixa de ser uma metáfora e começa a ganhar contornos mais nítidos. Ao partilhar a ideia, o indivíduo permite que ela ganhe forma e todos interajam em torno do que é possível. A ideia neste momento é incorporada ao grupo.

\subsubsection{Integração}

O foco desta etapa é a ação coletiva consciente. Neste momento a ideia que até então estava na mente ou no papel começa a se tornar realidade. A etapa de integração está no nível de grupo. As etapas de interpretação e de integração são passos que ocorrem 
entre a geração da ideia e a criação bem sucedida da empresa. Segundo Dutta e Crossan (2005), as ideias empreendedoras que passaram pelas etapas de interpretação e integração tem mais chance de sucesso, pois o empreendedor estaria aprendendo com as experiências de sua rede. Nesta etapa há um envolvimento mais intenso da rede do empreendedor na tentativa de decretar o que é possível, ou seja, tornar a ideia em algo real e prático.

\subsubsection{Institucionalização}

A última etapa acontece em nível organizacional. Nesta etapa, o conhecimento institucionalizado é incorporado à organização, os relacionamentos se tornam formalizados, surgem planos e outros sistemas formais e padronizados. Na etapa de institucionalização incluem-se as rotinas e os processos internos mais bem definidos, assim como os planos e as estratégias de expansão (DUTTA; CROSSAN, 2005).

\section{Metodologia}

Este estudo possui uma abordagem qualitativa e, quanto ao propósito, pode ser classificado como exploratório e descritivo. A pesquisa qualitativa "[...] não se preocupa com a representação numérica, mas sim com o aprofundamento da compreensão de um grupo social, de uma organização, etc." (GERHARDT; SILVEIRA, 2009, p. 31). A preocupação desta pesquisa foi, portanto, descrever o processo de identificação $e$ exploração de oportunidade segundo o modelo teórico 4i. Assim este estudo se insere no que diz Godoy (1995, p. 63), “[...] os pesquisadores qualitativos estão preocupados com o processo e não simplesmente com os resultados ou produto". Neuman (2010) afirma que a pesquisa descritiva é aquela que tem como objetivo descrever um fenômeno social e a pesquisa exploratória adota uma postura investigativa explorando várias fontes de informação.

A estratégia de pesquisa utilizada foi o estudo de caso único. O estudo de caso é uma estratégia de pesquisa que tem como foco compreender as dinâmicas presentes dentro de configurações individuais (EISENHARDT, 1989, p. 534). O estudo de caso único é utilizado quando ele representa um caso crítico, típico, extremo ou possui características únicas (SAUNDERS; LEWIS; THORNHILL, 2009). Por sua vez, Yin (2001) afirma que o estudo de caso único se justifica quando se deseja confirmar, contestar ou estender a teoria. Em função desses critérios, a escolha do caso deste estudo se deu por intencionalidade. Segundo Saunders, Lewis e Thornhill (2009), a escolha por intencionalidade permite que o pesquisador use o seu próprio julgamento para selecionar os casos que melhor lhe permitem responder a sua questão de pesquisa $e$ atendam seus objetivos. A empresa escolhida possuía algumas características que foram julgadas como adequadas ao estudo, tais como: ser um negócio inovador pois era o único na cidade à época em que foi aberto, não ser loja de franquia ou filial, ser de pequeno porte e com perspectiva de expansão.

Utilizou-se a entrevista semiestruturada em grupo como técnica de coleta de dados. Para Gerhardt e Silveira (2009, p. 72), a "[...] entrevista constitui uma técnica para se coletar dados não documentados sobre um tema específico". Na entrevista semiestruturada, as questões são mais espontâneas, segue-se uma sequencia mais livre, as perguntas são abertas e respondidas como em uma conversação informal (MARCONI; LAKATOS, 2003; TOZONI-REIS, 2009).

A entrevista em grupo é realizada com várias pessoas que respondem às perguntas simultaneamente de maneira informal (GERHARDT; SILVEIRA, 2009). Neste estudo, os sócios empreendedores foram entrevistados simultaneamente. Este método permitiu ganho de tempo e aprofundamento de algumas questões, pois um entrevistado complementava a resposta do outro, relembrando, clareando e reforçando pontos específicos na entrevista. As entrevistas foram gravadas, posteriormente transcritas e seu conteúdo foi analisado e as respostas agrupadas em categorias de análise.

Este estudo utilizou ainda a observação assistemática como outra técnica de coleta de dados. Segundo Marconi e Lakatos (2003), a observação é uma técnica usada para se conseguir informações e se vale dos sentidos na obtenção de determinados aspectos da realidade e não se limita apenas em ver e ouvir, mas também no exame de fatos ou fenômenos que se desejam estudar. A técnica da observação assistemática ou não estruturada pode ser chamada ainda de "[...] espontânea, informal, ordinária, simples, livre, ocasional e acidental, consiste em recolher e registrar os 
fatos da realidade sem que o pesquisador utilize meios técnicos especiais ou precise fazer perguntas diretas" (MARCONI; LAKATOS, 2003, p. 192). Os principais aspectos observados na pesquisa foram: o atendimento ao cliente e relações dos empreendedores com os funcionários, a estrutura física e administrativa $e$ as rotinas de trabalho. Essas observações foram inseridas na descrição e análise do caso.

A técnica de observação foi usada como complemento à entrevista. O uso de duas técnicas permite a triangulação de dados (SAUNDERS; LEWIS; THORNHILL, 2009), o que assegura maior validade e confiabilidade da pesquisa (PAIVA JÚNIOR; LEÃO; MELO, 2011).

Crossan, Lane e White (1999) apresentaram um quadro em que desenvolvem mais especificamente o "Modelo de Aprendizagem Organizacional 4i", composto de três dimensões (individual, grupo e organizacional), quatro categorias (intuição, interpretação, integração e institucionalização) e quatro elementos de análise (idealização, rede informal, rede formal e consolidação). O Quadro 1 foi adaptado do modelo original dos autores mencionados.

\begin{tabular}{|c|c|c|}
\hline Dimensões & CATEgorias & Elementos DE ANÁlise \\
\hline Individual & Intuição & Idealização do Negócio \\
\hline Grupo & Interpretação & Rede Informal \\
\hline Organizacional & Institucionalização & Consolidação da Ideia \\
\hline
\end{tabular}

Quadro 1: processo de aprendizagem organizacional 4i e oportunidade empreendedora

Fonte: Adaptado de Crossan, Lane e White (1999)

Segundo Tozoni-Reis (2009), a organização dos dados em categorias e elementos de análise permite facilidade na etapa de análise dos dados. Para uma melhor compreensão e definição dos elementos de análise que integram o Quadro 1, foram pesquisados outros autores na literatura relacionados a cada elemento de análise e, a partir destes elementos, foram elaboradas as questões da entrevista, conforme apresentados no Quadro 2. Como a entrevista foi semiestruturada, partiu-se de perguntas elaboradas, a priori, mas outras questões consideradas relevantes para um melhor entendimento do assunto foram formuladas no decorrer da entrevista.

\begin{tabular}{|c|c|c|}
\hline $\begin{array}{c}\text { Elementos de } \\
\text { AnÁlise }\end{array}$ & DEFINIÇÕES & $\begin{array}{l}\text { TópICOS Do Rotel- } \\
\text { RO DE ENTREVISTA }\end{array}$ \\
\hline 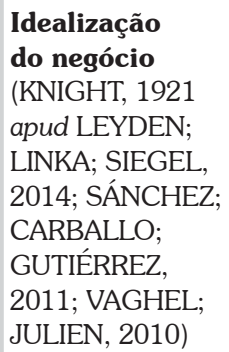 & $\begin{array}{l}\text { Surgimento da ideia, } \\
\text { experiência e análise } \\
\text { de mercado. }\end{array}$ & $\begin{array}{l}\text { Como surgiu a ideia } \\
\text { do negócio (quem, } \\
\text { quando, onde)? Foi } \\
\text { feita alguma pesqui- } \\
\text { sa ou observação } \\
\text { do mercado? Havia } \\
\text { experiência anterior? }\end{array}$ \\
\hline
\end{tabular}

\begin{tabular}{|c|c|c|}
\hline $\begin{array}{l}\text { Rede informal } \\
\text { (BIRLEY, 1985; } \\
\text { BORGES, 2011) }\end{array}$ & $\begin{array}{l}\text { Família e amigos } \\
\text { envolvidos que dão } \\
\text { apoio e ajudam a } \\
\text { desenvolver a ideia. }\end{array}$ & $\begin{array}{l}\text { A ideia foi compar- } \\
\text { tilhada inicialmente } \\
\text { com quem? Quem } \\
\text { foram as pessoas } \\
\text { envolvidas antes de } \\
\text { o negócio ser aber- } \\
\text { to? Quem aportou } \\
\text { recursos (materiais e } \\
\text { financeiros)? }\end{array}$ \\
\hline $\begin{array}{l}\text { Rede formal } \\
\text { (BIRLEY, 1985; } \\
\text { VASCONCELOS } \\
\text { et al., 2007) }\end{array}$ & $\begin{array}{l}\text { Organizações e ins- } \\
\text { tituições que auxilia- } \\
\text { ram o empreendedor } \\
\text { no desenvolvimento } \\
\text { da ideia; clientes, } \\
\text { funcionários, forne- } \\
\text { cedores e concorren- } \\
\text { tes envolvidos com o } \\
\text { negócio. }\end{array}$ & $\begin{array}{l}\text { Quem foram os ór- } \\
\text { gãos e demais pes- } \\
\text { soas envolvidas? Re- } \\
\text { lacionamento com } \\
\text { clientes? Recursos } \\
\text { humanos? Relacio- } \\
\text { namento com a Con- } \\
\text { corrência? }\end{array}$ \\
\hline 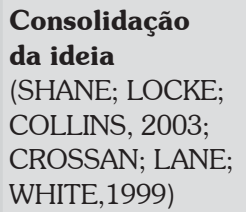 & $\begin{array}{l}\text { Gestão, estrutura or- } \\
\text { ganizacional, rotinas, } \\
\text { processos e estraté- } \\
\text { gias que contribuem } \\
\text { para consolidar a } \\
\text { ideia de negócio. }\end{array}$ & $\begin{array}{l}\text { Como está estrutu- } \\
\text { rada a gestão? Quais } \\
\text { as rotinas e processos } \\
\text { estão estruturados? } \\
\text { Estratégia de expan- } \\
\text { são? }\end{array}$ \\
\hline
\end{tabular}

Quadro 2: definições dos elementos de análise e tópicos do roteiro de entrevista

Fonte: Elaborado pelos autores com base na literatura

\section{Descrição do Caso}

O caso será descrito da seguinte forma: inicialmente serão apresentadas algumas características da empresa e dos empreendedores (sócios), e em seguida serão apresentadas as fases de: intuição, que se refere ao processo de idealização do negócio; interpretação, que trata dos laços informais envolvidos; integração, apresentando os laços formais envolvidos; e institucionalização, que mostra a consolidação da ideia. 


\section{DescriçÃo da EMPRESA E doS EMPREENDEDORES}

O Macarrones, fundada em 11 de agosto de 2011, é um restaurante especializado em massas do tipo macarrão, e até a data de abertura era a única empresa especializada nesse tipo de produto originalmente local. Está situada no bairro Sol Nascente, cidade de Aracaju-SE. Possui 13 funcionários fixos e 11 rotativos.

A empresa foi inaugurada, inicialmente com três sócios e atualmente está nas mãos de dois sócios (marido e mulher) que serão chamados neste estudo respectivamente de "empreendedor" [E1] e "empreendedora" [E2]. A empreendedora tem 34 anos e é natural de Salvador-BA e o empreendedor, 38 anos, natural de São Paulo-SP.

A seguir são destacadas as etapas do processo de Aprendizagem Organizacional 4i, conforme os dados levantados.

\subsection{Intuição (idealização do negócio)}

Nesta etapa buscou-se identificar a motivação empreendedora, como surgiu a ideia do empreendimento, mais especificamente quem teve a ideia e como foi influenciada pela experiência anterior e se houve uma busca deliberada para identificar a oportunidade.

Os entrevistados afirmaram que antes de abrir esse negócio especificamente, já tinham o desejo de empreender. A empreendedora, por exemplo, afirmou que a vontade era abrir um negócio no ramo de calçados, bolsas ou floricultura.

Quanto à motivação, o principal fator foi o desejo de liberdade, a independência de fazerem o que quisessem sem terem patrão e também devido à insegurança e insatisfação no emprego, como afirmaram:

É duro quando a gente se esforça, acorda cedo, se dedica àquela empresa e do nada ela chega e te diz: "você tá demitido". Então ela veio e disse: "vamos abrir algo prá gente, vamos tentar". Porque ela sabe o sacrifício, a luta que eu tinha [...] e a gente ficava triste com isso. Por isso que nós resolvemos montar um negócio próprio. [E1]

A ideia inicial do negócio foi do irmão da empreendedora, que viu esse modelo num outro estado e compartilhou essa ideia com os demais membros da família. Pode-se dizer que o irmão fez uma busca deliberada, ou seja, proposital a fim de descobrir uma oportunidade de negócio. A partir daí houve uma pesquisa sobre o tipo de negócio e principalmente acerca do produto, que passou a ser produzido e testado em casa. Quanto à experiência anterior, apenas o empreendedor possuía, pois já havia trabalhado no comércio do pai dos doze aos vinte anos.

\subsection{Interpretação (redes informais)}

Nesta fase buscou-se identificar quem foram as pessoas da rede informal do empreendedor a quem a ideia foi transmitida inicialmente. Segundo o casal de empreendedores, assim que o irmão da empreendedora observou a ideia, logo os membros da família foram comunicados e a oportunidade foi identificada. Os familiares envolvidos foram, além do casal e do irmão, o pai, a mãe e a cunhada da empreendedora. Todos eles compartilharam a ideia inicial. $\mathrm{O}$ apoio dos pais da empreendedora é enfatizado por ela:

Meus pais ajudaram muito a gente no início, quando precisava, quando apertava um pouquinho eles estavam sempre ali ajudando e dizendo "vamos, vamos!" [E2]

No início foi formada uma sociedade entre os pais da empreendedora (representada por seu irmão) e seu marido (empreendedor). Mais adiante, a sociedade foi rompida e o empreendedor ficou com a parte do irmão da empreendedora.

\subsection{Integração (redes formais)}

Nesta fase foram observados quais os laços formais que os empreendedores formaram no desenvolvimento da ideia. Especificamente procurou-se identificar que instituições/ organizações foram procuradas pelos empreendedores para auxiliar no desenvolvimento do negócio. Também se verificou nesta fase o relacionamento com a clientela, funcionários, fornecedores e concorrentes.

Quanto aos laços formais foram acionadas três instituições: Banco, Serviço Brasileiro de Apoio à Micro e Pequena Empresa (SEBRAE) e Serviço Nacional de Aprendizagem Comercial (SENAC). O banco foi procurado quando o empreendedor precisou pegar um empréstimo para investir num novo ponto. No 
SENAC eles foram em busca das normas de boas práticas de manipulação de alimentos. Já o SEBRAE foi procurado pelos empreendedores com o objetivo de prestar consultoria quanto à arquitetura do ambiente.

Os clientes, por sua vez, são considerados atores importantes para a empresa. Segundo os empreendedores, os clientes são a maior fonte de conhecimento, conforme atestam:

A gente aprendeu muito com nossos clientes no dia-a-dia [...]. A nossa forma de abordar o cliente, a gente pergunta se o cliente tá satisfeito ou não, então a gente deixa o cliente a vontade de criticar, de dar uma sugestão. Então o cliente trás muitas informações importantes, muito boas prá gente. [...] a gente até comenta que os clientes não são nossos clientes, eles acabam virando nossos amigos mesmo porque eles se sentem a vontade de chegar, de dizer: "oh, aconteceu isso, não gostei disso", e a gente tenta melhorar. O estreitamento da relação da gente com os clientes é uma coisa boa, não é aquela coisa impessoal que o cliente chega come e vai embora, você não sabe quem é o ciente, o cliente não sabe quem é você. Não! O cliente chega aqui, cada um tem o seu nome [...] então a gente tenta ter essa aproximação com o cliente. [E1]

Foi possível identificar por meio da observação que há boa interação entre os empreendedores e os clientes. A empreendedora, que por vezes assume a função de caixa, demonstra muita simpatia para com todos. O empreendedor, sempre que possível percorre algumas mesas dialogando com os clientes.

Com exceção de um carro de som e alguns panfletos distribuídos no início, a estratégia de propaganda utilizada foi o "boca a boca". Segundo os empreendedores, por se tratar de um produto diferenciado, ele precisa ter excelente qualidade para que o "boca a boca" dê certo. Como a clientela tem aumentado isso atesta que de fato o produto tem qualidade e a propaganda "boca a boca" tem funcionado. Inclusive clientes que frequentaram o primeiro ponto continuaram fiéis voltando com a inauguração do novo local. A demanda de clientes é bastante diversificada.

Uma grande preocupação observada é em relação aos recursos humanos. Por diversas vezes os empreendedores citaram a forma como se relacionam com os funcionários:
"Em relação aos nossos funcionários, a gente procura respeitar muito porque são nossos parceiros, sem eles...". [E1]

Uma das preocupações em relação aos funcionários, diz respeito aos salários:

Uma coisa que a gente se preocupa muito até hoje mesmo com os nossos funcionários é a questão dos salários deles também [...], então uma coisa que a gente prioriza aqui é o salário dos funcionários, então a gente paga em dia ou até antes se for o caso. [E2]

Observou-se que o relacionamento entre patrões (empreendedores) e funcionários é realmente tranquilo. Há respeito entre ambas as partes, há boa comunicação interpessoal e os empreendedores estão sempre próximos e não distantes e isolados no escritório.

Quanto aos concorrentes, eles serviram como fonte de inspiração. Observar os concorrentes serviu como aprendizado. Quanto a este aspecto afirmaram:

A gente se espelhava muito na concorrência, principalmente nos grandes, o que eles fazem para agradar os clientes. Então a gente mesmo começou a aprender com eles [...], a gente passava num ponto, no outro, olhávamos: "aquilo ali tá legal, aquilo não". Então a gente foi tentando trazer prá cá a experiência de cada um. [E1]

Os concorrentes mencionados foram redes de restaurantes, lanchonetes e outras empresas do segmento que ofereciam diversos tipos de produtos. Havia apenas um concorrente cujo negócio se assemelhava parcialmente mesmo assim com um formato diferenciado principalmente em relação ao mix de produtos e atendimento. Entretanto, com o sucesso do empreendimento surgiram concorrentes seguidores que entraram no mercado copiando o mesmo modelo de negócio. A relação com tais concorrentes é de respeito, embora certo concorrente tenha utilizado práticas desleais para atrair clientes e funcionários do Macarrones. A concorrência é vista como importante até para que eles não relaxem e mantenham sempre a qualidade do produto tendo-o sempre como um diferencial.

Quanto aos fornecedores, são cerca de quatorze e a relação é bastante profissional. Há bastante preocupação com a negociação e compras de produtos. Geralmente, produtos e alimentos que são usados 
no dia a dia são adquiridos à vista o que diminui os custos, porém equipamentos mais caros são comprados em parcelas de no máximo seis parcelas.

\subsection{Institucionalização (consolidação da ideia)}

Nesta etapa foram verificados como foram estruturadas a gestão, as rotinas e processos organizacionais, e quais as estratégias para crescimento do empreendimento.

Quanto a gestão da empresa, o empreendedor cuida da produção e do atendimento, a empreendedora é responsável pelo financeiro e controle de qualidade e há ainda o apoio de uma cunhada.

Observou-se que a administração, embora ainda não profissionalizada, tem uma estrutura organizada, com funções bem definidas, evitando a sobreposição de funções, ainda que um sempre ajude o outro. Há salas específicas para o setor administrativo onde são guardados documentos e executadas as atividades de escritório.

Quanto às rotinas e processos foi possível observar que a empresa já atingiu certo grau de organização no atendimento ao cliente, administração e recursos humanos. Quanto ao modelo de atendimento eles citam que muitas mudanças e melhorias aplicadas surgiram a partir de sugestões de clientes. Uma das características observadas é que os empreendedores estão sempre abertos a ouvir os clientes e funcionários e aprender constantemente, melhorando continuamente o negócio.

Sobre planos para o futuro da empresa eles citaram quatro estratégias para crescimento e expansão do negócio: abertura de filial, lançamento de novos produtos, criação de franquia e profissionalização do negócio. Dessas quatro estratégias a abertura de filial é a que já está sendo colocada em ação. Sobre este assunto comentaram:

A gente começou do nada, a gente não é uma empresa rica que tem um capital que vem do nada e monta tudo de vez [...]. A gente veio fazendo as coisas aos pouquinhos. Lá não, lá a gente já está com experiência e vai fazer do nosso jeito. [E1]
Quanto a franquia da marca eles citaram que foi pedido registro e que há interessados em outros estados. O lançamento de novos produtos por sua vez está condicionado à abertura da filial e reforma que será feita no ponto atual. Por fim eles citaram que pretendem profissionalizar ainda mais o negócio organizando por setores e contratando profissionais para cuidar da gestão da empresa. Finalizando eles falaram sobre a importância de estabelecerem metas e de sonharem alto:

Se a gente não tivesse pensado em chegar em algum lugar não teríamos chegado onde a gente está. A gente só consegue chegar se a gente sonhar. Então a gente tem que sonhar, idealizar primeiro e tentar chegar o mais próximo possível daquilo que a gente pensa. [E2]

Nesta fase foi possível observar que a empresa é bastante organizada, tanto administrativa, quanto fisicamente. Os empreendedores demonstraram ter "pés no chão" e possuir metas claras para o futuro do empreendimento.

\section{Conclusão}

Neste estudo buscou-se analisar o processo de identificação e exploração de oportunidade empreendedora por parte de dois pequenos empreendedores segundo o Modelo de Aprendizagem Organizacional 4i de Crossan, Lane e White. Foi verificado como a oportunidade empreendedora se desenvolveu ao logo de um processo com quatro fases: intuição, interpretação, integração e institucionalização.

Observou-se que na fase de intuição a ideia foi gerada com base na observação e na busca deliberada, ou seja, o empreendedor procurou de forma proposital a oportunidade. A segunda fase - interpretação - envolveu a rede informal do empreendedor. Várias pessoas, principalmente da família se envolveram para que a ideia se concretizasse. Na terceira fase - de integração - foi possível verificar como o empreendedor buscou suporte de instituições como banco, SEBRAE e SENAC. Também foi destacada nesta fase a relação positiva com os clientes tidos como grande fonte de informações, bem como funcionários, fornecedores e empresas concorrentes, que serviram como fonte de ideias. Na quarta e última fase - institucionalização - 
verificou-se os aspectos de gestão e processos internos, bem como os planos de expansão do negócio. Como planos de expansão foram citados a abertura de filial, lançamento de novos produtos, abertura de franquia e profissionalização do negócio.

A partir do caso analisado, percebeu-se que o reconhecimento da oportunidade por parte do empreendedor foi baseado na sua intuição e que, para que se concretizasse, foi necessário desenvolver vínculos de colaboração com várias partes interessadas, semelhante ao destacado por Dutta e Crossan (2005). Foi possível verificar ainda que, como a aprendizagem organizacional evoluiu por todas as fases do modelo, passando pelos diversos atores envolvidos na identificação e exploração da oportunidade, se incorporou à organização por meio de processo de feedback, conforme as premissas formuladas por Crossan, Lane e White (1999).

A principal contribuição deste estudo é ampliar o conhecimento sobre o fenômeno do empreendedorismo, mais especificamente sobre as oportunidades empreendedoras. Também contribui na medida em que adota o Modelo de Aprendizagem Organizacional 4i) em um caso, permitindo aprofundar a compreensão do fenômeno. Pode-se ainda, a partir desse estudo de caso, ampliar a percepção das oportunidades empreendedoras estudando o papel dos múltiplos atores do processo de aprendizagem organizacional. Por fim, vale ressaltar que o presente estudo pretende servir ainda, como ponto de partida para futuras pesquisas que explorem esse modelo e consigam construir uma ponte mais sólida entre os campos do empreendedorismo $e$ da aprendizagem organizacional.

\section{REFERÊNCIAS}

ALVAREZ, S. A.; BARNEY, J. B. Discovery and creation: Alternative theories of entrepreneurial action. Strategic entrepreneurship journal, [S.I.], v. 1, n. 1-2, p. 11-26, 2007.

AUDRETSCH, D. B.; ACS, Z. J. Handbook of entrepreneurship research. An interdisciplinary survey and introduction. ed. 2. Springer: [s.n.], 2003.
BARON, R. A. Opportunity Recognition as Pattern Recognition: How Entrepreneurs "Connect the Dots" to Identify New Business Opportunities. Academy of Management Perspectives, [S.I.], v. 20, n. 1, p. 104119, 2006.

BARON, R. A.; SHANE S. A. Empreendedorismo: uma visão do processo. Cengage Learning: São Paulo, 2007.

BIRLEY, S. The role of networks in the entrepreneurial process. Journal of Business Venturing, [S.l.], v. 1, n. 1, p. 107-117, 1985.

BORGES, C. O papel do capital social do empreendedor na criação de empresas tecnológicas. Revista de Administração e Inovação, São Paulo, v. 8, n. 2, p.162181, jul.-set. 2011.

CAMPOS, H. M.; PARELLADA, F. S.; PALMA, Y. Mapping the intellectual structure of entrepreneurship research: revisiting the invisible college. Review of Business Management, [S.I.], v. 14, n. 42, p. 41-58, 2012.

CORBETT, A. C. Experiential learning within the process of opportunity identification and exploitation. Entrepreneurship Theory and Practice, [S.l.], v. 29, n. 4, p. 473-491, 2005.

CORBETT, A. C. Learning asymmetries and the discovery of entrepreneurial opportunities. Journal of Business Venturing, [S.I.], v. 22, n. 1, p. 97-118, 2007.

CORRÊA, V. S.; VALE, G. M. V. A dinâmica das motivações empreendedoras: uma investigação retrospectiva. Revista Pretexto, [S.I.], v. 14, n. 4, p. 1128, 2014.

CROSSAN, M. M.; LANE, H. W.; WHITE, R. E. An organizational learning framework: from intuition to institution. Academy of Management Review, [S.I.], v. 24, n. 3, p. 522-537, 1999.

DIMOV, D. Beyond the Single-Person, SingleInsight Attribution in Understanding Entrepreneurial Opportunities. Entrepreneurship Theory and Practice, [S.l.], v. 31, n. 5, p. 713-731, 2007a.

From Opportunity Insight to Opportunity Intention: The Importance of Person-Situation Learning Match. Entrepreneurship Theory and Practice, [S.I.], v. 31, n. 4, p. 561-583, $2007 b$. 
DUTTA, D. K.; CROSSAN, M. M. The Nature of Entrepreneurial Opportunities: Understanding the Process Using the 4I Organizational Learning Framework. Entrepreneurship Theory and Practice, [S.I.], v. 29, n. 4, p. 425-449, 2005.

ECKHARDT, J. T.; SHANE, S. A. Opportunities and Entrepreneurship. Journal of Management, [S.l.], v. 29, n. 3, p. 333-349, 2003.

EDELMAN, L.; RENKO H. Y. The Impact of Environment and Entrepreneurial Perceptions on Venture-Creation Efforts: Bridging the Discovery and Creation Views of Entrepreneurship. Entrepreneurship Theory and Practice, [S.l.], v. 34, n. 5, p. 833-856, 2010.

EISENHARDT, K. M. Building theories from case study research. Academy of Management Review, [S.I.], v. 14, n. 4, p. 532-550, 1989.

FABRÍCIO, J. S.; MACHADO, H. P. V. Exploração de Oportunidade e Inovação: um Estudo de Caso no Setor Ervateiro. In: ENCONTRO DE ESTUDOS SOBRE EMPREENDEDORISMO E PEQUENAS EMPRESAS, 6., 2010, Recife. Anais... Recife: EGEPE, 2010. p. 1-14.

FAIA, V. S; ROSA, M. A. G.; MACHADO, H. P. V. Alerta Empreendedor e as Abordagens Causation e Effectuation sobre Empreendedorismo. Revista de Administração Contemporânea, [S.I.], v. 18, n. 2, p. 196-216, 2014.

FILION, L. J. From entrepreneurship to

entreprenology. Montréal: École des hautes études commerciales, Chaire d'entrepreneurship. Maclean Hunter, 1997.

GARTNER, W. B. Who is an entrepreneur? Is the wrong question. American Journal of Small Business, [S.l.], v. 12, n. 4, p. 11-32, 1988.

\section{GEM. Global Entrepreneurship Monitor:}

Empreendedorismo no Brasil - relatório executivo. Paraná: Universidade Federal do Paraná, 2013. 19 p.

GERHARDT, T. E.; SILVEIRA, D. T. Métodos de pesquisa. [S.l.]: Plageder, 2009.

GODOY, A. S. Introdução à pesquisa qualitativa e suas possibilidades. Revista de Administração de Empresas, [S.l.], v. 35, n. 2, p. 57-63, 1995.
KOLB, D. A. Experiential learning: experience as the source of learning and development. Englewood Cliffs, NJ: Prentice-Hall, 1984.

LEYDEN, D. P.; LINK, A. N.; SIEGEL, D. S. A theoretical analysis of the role of social networks inentrepreneurship. Research Policy, [S.l.], p. 1157-1163, 2014.

LOW, M. B.; MACMILLAN, I. C. Entrepreneurship: Past research and future challenges. Journal of Management, [S.l.], v. 14, n. 2, p. 139-161, 1988.

LUMPKIN, G. T.; LICHTENSTEIN, B. B. The role of organizational learning in the Opportunity $\square$ Recognition process. Entrepreneurship Theory and Practice, [S.l.], v. 29 , n. 4 , p. $451-472,2005$.

\section{MACHADO, H. P. V. (Org.). Empreendedorismo,} oportunidades e cultura: seleção de casos no contexto brasileiro. Eduem: Maringá, 2013. 211 p.

\section{MARCONI, M. A.; LAKATOS, E. M. Fundamentos de}

Metodologia Científica. Atlas S.A., São Paulo, ed. 5, 2003.

MITCHELL, R. K. et al. Toward a theory of entrepreneurial cognition: Rethinking the people side of entrepreneurship research. Entrepreneurship theory and practice, [S.l.], v. 27 , n. 2, p. 93-104, 2002.

\section{NEUMAN, Lawrence W. Social Research Methods:} qualitative and quantitative approaches. 7. ed. [S.I.]: Pearson Higher Ed USA, 2010.

PAIVA JÚNIOR, F. G.; LEÃO, A. L. M. S.; MELLO, S. C. B. Validade e Confiabilidade na Pesquisa Qualitativa em Administração. Revista de Ciências da Administração, [S.l.], v. 13, n. 31, p. 190-209, set.-dez. 2011.

RAE, D. Entrepreneurial learning: a narrative-based conceptual model. Journal of Small Business and Enterprise Development, [S.I.], v. 12, n. 3, p. 323-335, 2005.

SÁNCHEZ, J. C.; CARBALLO, T.; GUTIÉRREZ, A. The entrepreneur from a cognitive approach. Psicothema, [S.l.], v. 23, n. 3, p. 433-438, 2011.

SARASON, Y.; DEAN, T.; DILLARD, J. F.

Entrepreneurship as the nexus of individual and opportunity: A structuration view. Journal of Business Venturing, [S.l.], v. 21, n. 3, p. 286-305, 2006. 
SARASVATHY, S. D. Causation and effectuation:

Toward a theoretical shift from economic inevitability to entrepreneurial contingency. Academy of management Review, [S.l.], v. 26, n. 2, p. 243-263, 2001.

SAUNDERS, M.; LEWIS, P.; THORNHILL, A. Research methods for business students. 5. ed. [S.l.]: Pearson Education Limited, 2009.

SHANE, S.; VENKATARAMAN, S. The promise of entrepreneurship as a field of research. Academy Of Management Review, [S.I.], v. 25, n. 1, p. 217-226, 2000 .

SHANE, S.; LOCKE, E. A.; COLLINS, C. J. Entrepreneurial motivation. Human Resource

Management Review, [S.1.], v. 13, n. 2, p. 257-279, 2003.

SHANE, S. Prior knowledge and the discovery of entrepreneurial opportunities. Organization science, [S.l.], v. 11, n. 4, p. 448-469, 2000.

SHEPHERD, D. A.; DETIENNE, D. R. Prior knowledge, potential financial reward, and opportunity identification. Entrepreneurship Theory and Practice, [S.l.], v. 29, n. 1, p. 91-112, 2005.

SHORT, J. C. et al. The Concept of "Opportunity" in Entrepreneurship Research: Past Accomplishments and Future Challenges. Journal of Management, [S.I.], 2010.

SMITH, B. R.; MATTHEWS, C. H.; SCHENKEL, M. T. Differences in Entrepreneurial Opportunities: The Role of Tacitness and Codification in Opportunity Identification. Journal of Small Business Management, [S.l.], v. 47, n. 1, p. 38-57, 2009.

TANG, J.; KACMAR, K. M; BUSENITZ, L. Entrepreneurial alertness in the pursuit of new opportunities. Journal of

Business Venturing, [S.I.], v. 27, n. 1, p. 77-94, 2012.

TOZONI-REIS, M. F. C. Metodologia da pesquisa. 2. ed. Curitiba: IESDE Brasil S/A, 2009.

UCBASARAN, D.; WESTHEAD, P.; WRIGHT, M.

The extent and nature of opportunity identification by experienced entrepreneurs. Journal of Business

Venturing, [S.l.], v. 24, n. 2, p. 99-115, 2009.
VAGHELY, I. P.; JULIEN, P. A. Are opportunities recognized or constructed? An information perspective on entrepreneurial opportunity identification. Journal of Business Venturing, [S.l.], v. 25, n. 1, p. 73-86, 2010.

VALLIERE, D. Towards a schematic theory of entrepreneurial alertness. Journal of Business Venturing, [S.l.], v. 28, n. 3, p. 430-442, 2013.

VASCONCELOS, G. M. R. et al. Mobilizando relacionamentos e acessando recursos na criação e evolução de novos negócios. Organizações \& Sociedade, [S.1.], v. 14, n. 41, abr.-jun. 2007.

YIN, R. K. Estudo de Caso: planejamento e método. 2. ed. Porto Alegre: Bookman, 2001. 